\title{
Hemostatic agents used in apical surgery: a review.
}

\author{
Laura Maestre-Ferrín ${ }^{1}$, María Peñarrocha-Diago ${ }^{2}$ \\ ${ }^{1}$ Master in Oral Surgery and Implantology. Valencia University Medical and Dental School, Valencia, Spain. \\ ${ }^{2}$ Associate Professor of Oral Surgery. Master in Oral Surgery and Implantology. Valencia University Medical and Dental School, \\ Valencia, Spain.
}

Correspondence:

Clínicas Odontológicas

Gascó Oliag 1

46021-Valencia (Spain)

Phone and fax: +34-96-3864139

E-mail: maria.penarrocha@uv.es

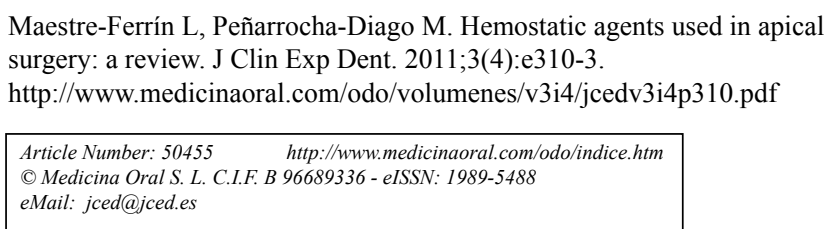

\begin{abstract}
Objective: A review was made of the current literature on hemostatic agents used in apical surgery in order to determine their effectiveness and adverse effects.

Material and methods: The main search terms used were: endodontic surgery, apicoectomy, apical surgery, periradicular surgery, hemostasis, hemostatic agents, and bleeding control. The authors searched the Medline database for articles published up to 1 September 2010. Experimental and clinical studies comparing the effectiveness and/ or adverse effects of two or more hemostatic agents and published between 2000 and 2010 were included in the review.

Results: Four studies were analyzed: two clinical studies and two experimental studies. According to the clinical studies, epinephrine produces no changes in blood pressure or heart rate when used to control bleeding in periapical surgery. Aluminum chloride alone or in combination with ferric sulfate was found to be the most effective agent in the experimental studies, and the tissue damage it causes was not observed when the superficial bone layer was eliminated with rotary instruments.

Conclusion: Additional controlled clinical trials are needed to not only assess the efficacy of the different hemostatic agents but also to investigate their influence upon healing and the outcome of periapical surgery.
\end{abstract}

Key words: Periradicular surgery, hemostatic agents, endodontic surgery, hemostasis. 


\section{Introduction}

Adequate bleeding control is essential in order to ensure the success of periapical surgery, since it improves visualization of the surgical field, shortens surgery time, facilitates retrograde cavity preparation, and is necessary for the insertion of most retrograde filling materials. In addition, correct bleeding control lessens blood loss during surgery, as well as postoperative bleeding and postoperative inflammation (1).

Different studies have examined the tissue reactions to hemostatic agents (2-9), as well as the systemic effects and clinical efficacy of these agents when used in the context of periapical surgery $(10,11)$. Bone wax was introduced to control bone crypt bleeding in periapical surgery by Selden (12) in 1970, but bone healing is poor in the presence of this material; connective tissue fibers appear; and there is no bone or hematopoietic tissue presence (5). In addition to delaying healing, bone wax increases the susceptibility to infection (13) and causes chronic inflammation with foreign body reactions $(5,6$, 14). Ferric sulfate is one of the few materials to have been specifically studied in application to periapical surgery. Lemon et al. (8) and Jeansonne et al. (7) studied the effects of ferric sulfate in rabbit periapical tissues, achieving hemostasis for 5 minutes and normal healing, with mild foreign body reaction - provided careful curettage of the cavity was performed, and saline solution irrigation was used. The amine-type sympathomimetic vasoconstrictors such as epinephrine, norepinephrine and phenylephrine have been used as topical agents for the control of bleeding in periapical surgery (15). Epinephrine induces vasoconstriction through the stimulation of $\alpha$-adrenergic receptors. Besner (16) suggested that the use of this drug in periapical surgery might induce a systemic cardiovascular response.

Kim and Rethnam (15) reported that a good hemostatic agent should stop bleeding in a short period of time, be easy to handle, should be biocompatible, should not delay or complicate healing, and should be relatively inexpensive and safe. Apparently, no hemostatic agent meets all these conditions, because all of them produce adverse effects in varying degrees - this posing a dilemma for clinicians when having to chose a hemostatic product. The present review examines the current literature on hemostatic agents used in apical surgery in order to determine their effectiveness and adverse effects

\section{Material and methods}

The main search terms used were: endodontic surgery, apicoectomy, apical surgery, periradicular surgery, hemostasis, hemostatic agents, bleeding control. These terms were used in combination as follows: hemostasis and apical surgery; hemostasis and endodontic surgery; hemostasis and apicoectomy; hemostatic agents and apical surgery; hemostatic agents and endodontic surgery; hemostatic agents and apicoectomy; bleeding control and endodontic surgery; bleeding control and apical surgery; bleeding control and apicoectomy; and hemostatic agents and periradicular surgery. The authors searched the Medline database by applying Entrez PubMed limits to "Dental journals"; the last search was conducted on 1 September 2010.

This review aimed at including experimental studies and clinical studies comparing the effectiveness and/or adverse effects of two or more hemostatic agents, and which had been published in dental journals between 2000 and 2010.

\begin{tabular}{|l|c|}
\hline \multicolumn{1}{|c|}{ Search terms } & $\begin{array}{c}\text { Number } \\
\text { of articles } \\
\text { found }\end{array}$ \\
\hline Hemostasis, apical surgery & 9 \\
\hline Hemostasis, endodontic surgery & 13 \\
\hline Hemostasis, apicoectomy & 10 \\
\hline Hemostatic agents, apical surgery & 8 \\
\hline Hemostatic agents, endodontic surgery & 8 \\
\hline Hemostatic agents, apicoectomy & 7 \\
\hline Bleeding control, endodontic surgery & 11 \\
\hline Bleeding control, apical surgery & 5 \\
\hline Bleeding control, apicoectomy & 9 \\
\hline Hemostatic agents, periradicular surgery & 3 \\
\hline
\end{tabular}

Table 1. Number of articles found in the Medline database with different search terms (the search was limited to articles published in dental journals).

\section{Results}

Table 1 shows the results of the electronic search strategy. From the analysis of the titles of the studies, only 12 papers were identified as eligible for inclusion in this review $(1,10-12,15-22)$. Seven of them were excluded because they were published before year $2000(1,12$, 15-19). After reading the abstracts, one study was excluded because it did not compare two hemostatic agents and it was made in postextraction sites (21). Finally, four studies were included for review $(10,11,20,22)$ : two were clinical studies $(10,11)$ and two experimental studies $(20,22)$.

Vickers et al. (10) evaluated the hemostatic efficacy and the cardiovascular effects of ferric sulfate and of cotton balls impregnated with racemic epinephrine. The study involved 39 patients randomized to one group or the other. Both agents produced surgical hemostasis, and there were no significant changes in the systemic cardiovascular with either product. In a similar study, Vy et al. (11) compared Collacote ${ }^{\circledR}$ collagen sponges impregnated with $2.25 \%$ racemic epinephrine versus the same sponges impregnated with saline solution. A total of 48 patients were studied (42 in the epinephrine group and 6 in the saline control group). No differences were found 
between the two groups in terms of either blood pressure or heart rate. Good bleeding control was not achieved in three of the 42 patients of the epinephrine group and in 5 of the 6 subjects in the control group. The authors concluded that collagen sponges saturated with epinephrine afford excellent bleeding control and induce no evident changes in blood pressure or heart rate.

The two experimental studies were carried out in rabbit skulls, testing a material which von Arx had started to use in 2001 (20): a paste containing aluminum chloride and kaolin, and which clinically proved to be very effective (20). This product is known as Expasyl ${ }^{\circledR}$, and is usually used to produce gingival retraction $(23,24)$. Von Arx et al. (20) compared the hemostatic efficacy and tissue reactions of bone wax, ferric sulfate (Stasis ${ }^{\circledR}$ ), Expasyl ${ }^{\circledR}$, and a combination of Expasyl ${ }^{\circledR}$ and ferric sulfate (since in some cases they had used both products synergically to control recurrent bleeding). Expasyl $\mathbb{}$ alone or in combination with ferric sulfate was found to be the most effective agent, and the inflammatory tissue reactions were limited to the bone defects - never extending towards the surrounding tissues. The authors recommend cleaning the bone cavity with a curette and freshening the bone with a round drill before closing the wound. Although in their study these procedures were not used for the complete elimination of Expasyl ${ }^{\circledR}$, no acute or chronic tissue reactions were observed in the medullary spaces around the bone defects. The authors therefore considered that the adverse effects of Expas$y l \circledast$ could be avoided by freshening the bone crypt as commented above. In order to explore this hypothesis, Jensen et al. (22) used the same study design, comparing the effects of 5 hemostatic protocols: Expasyl ${ }^{\circledR}+$ Stasis ${ }^{\circledR}$, Expasyl ${ }^{\circledR}+$ Stasis ${ }^{\circledR}+$ bone crypt freshening with a drill, Spongostan $\AA$, Spongostan $®+$ epinephrine, and electrocautery. The most effective methods for reducing bleeding were Expasyl ${ }^{\circledR}+$ Stasis ${ }^{\circledR}$ and electrocautery, but these procedures triggered adverse tissue reactions (necrotic bone, inflammatory cells, absence of bone repair). Such tissue damage was not observed when the superficial bone layer was removed with rotary instrumentation, however.

\section{Discussion}

The studies on the efficacy and adverse effects of the hemostatic agents used in periapical surgery are very few. In the light of the results of the clinical studies included in the present review $(10,11)$, it can be affirmed that the amine-type sympathomimetic vasoconstrictors such as epinephrine produce no changes in blood pressure or heart rate when used to control bleeding in periapical surgery.

The introduction of Expasyl ${ }^{\circledR}$ as a hemostatic agent in periapical surgery is recent, and no clinical studies have been published on the efficacy and adverse reactions of this material. According to the findings of experimental studies, it appears to be the most effective of all the options presently used for bleeding control in this type of surgery, and the foreign body reactions that appear when Expasyl ${ }^{\circledR}$ is used can be avoided by freshening the bone crypt with rotary instruments and irrigation before suturing $(20,22)$.

Only one study (25) has correlated the prognosis of periapical surgery to the use of hemostatic agents. For controlling bone crypt hemorrhage, the authors used gauze impregnated with epinephrine or ferric sulfate. Evaluation was made according to whether some material had been used or not, without specifying the result of each of them. The authors found that the use of a hemostatic agent was not predictive of the outcome of periapical surgery. Von Arx et al. (26) used aluminum chloride (Expasyl ${ }^{\circledR}$ ) and/or ferric sulfate for bleeding control during periapical surgery of 194 human teeth, with a success rate of $90.2 \%$, though the influence of the hemostatic agent upon the outcome of surgery was not analyzed.

In order to determine which hemostatic agent is best, controlled clinical trials must be carried out to evaluate not only the efficacy of each material but also its influence upon healing and the outcome of periapical surgery.

\section{References}

1. Witherspoon DE, Gutmann JL. Haemostasis in periradicular surgery. Int Endod J. 1996;29:135-49.

2. Ibarrola JL, Bjorenson JE, Austin BP, Gerstein H. Osseous reactions to three hemostatic agents. J Endod. 1985;11:75-83.

3. Alberius $P$, Klinge B, Sjögren S. Effects of bone wax on rabbit cranial bone lesions. J Craniomaxillofac Surg. 1987;15:63-7.

4. Haasch GC, Gerstein H, Austin BP. Effects of two hemostatic agents on osseous healing. J Endod. 1989;15:310-4.

5. Finn MD, Schow SR, Schneiderman ED. Osseous regeneration in the presence of four common hemostatic agents. J Oral Maxillofac Surg. 1992;50:608-12.

6. Solheim E, Pinholt EM, Bang G, Sudmann E. Effect of local hemostatics on bone induction in rats: a comparative study of bone wax, fibrin-collagen paste, and bioerodible polyorthoester with and without gentamicin. J Biomed Mater Res. 1992;26:791-800.

7. Jeansonne BG, Boggs WS, Lemon RR. Ferric sulfate hemostasis: effect on osseous wound healing. II. With curettage and irrigation. J Endod. 1993;19:174-6.

8. Lemon RR, Steele PJ, Jeansonne BG. Ferric sulfate hemostasis: effect on osseous wound healing. Left in situ for maximum exposure. J Endod. 1993;19:170-3.

9. Allison RT. Foreign body reactions and an associated histological artefact due to bone wax. Br J Biomed Sci. 1994;51:14-7.

10. Vickers FJ, Baumgartner JC, Marshall G. Hemostatic efficacy and cardiovascular effects of agents used during endodontic surgery. $\mathrm{J}$ Endod. 2002;28:322-3.

11. Vy CH, Baumgartner JC, Marshall JG. Cardiovascular effects and efficacy of a hemostatic agent in periradicular surgery. J Endod. 2004;30:379-83.

12. Selden HS. Bone wax as an effective hemostat in periapical surgery. Oral Surg Oral Med Oral Pathol. 1970;29:262-4.

13. Nelson DR, Buxton TB, Luu QN, Rissing JP. The promotional effect of bone wax on experimental Staphylococcus aureus osteomyelitis. J Thorac Cardiovasc Surg. 1990;99:977-80.

14. Aurelio J, Chenail B, Gerstein H. Foreign-body reaction to bone wax. Report of a case. Oral Surg Oral Med Oral Pathol. 1984;58:98100. 
15. Kim S, Rethnam S. Hemostasis in endodontic microsurgery. Dent Clin North Am. 1997;41:499-511.

16.16. Besner E. Systemic effects of racemic epinephrine when applied to the bone cavity during periapical surgery. Va Dent J. 1972;49:9-12.

17. Gutmann JL. Parameters of achieving quality anesthesia and hemostasis in surgical endodontics. Anesth Pain Control Dent. 1993;2:223-6.

18. Odell EW, Oades P, Lombardi T. Symptomatic foreign body reaction to haemostatic alginate. $\mathrm{Br} \mathrm{J}$ Oral Maxillofac Surg. 1994;32:178-9.

19. Sauveur G, Roth F, Sobel M, Boucher Y. The control of haemorrhage at the operative site during periradicular surgery. Int Endod J. 1999;32:225-8.

20. von Arx T, Jensen SS, Hänni S, Schenk RK. Haemostatic agents used in periradicular surgery: an experimental study of their efficacy and tissue reactions. Int Endod J. 2006;39:800-8.

21. Puia SA, Renou SJ, Rey EA, Guglielmotti MB, Bozzini CE. Effect of bismuth subgallate (a hemostatic agent) on bone repair; a histologic, radiographic and histomorphometric study in rats. Int $\mathbf{J}$ Maxillofac Surg. 2009;38:785-9.

22. Jensen SS, Yazdi PM, Hjørting-Hansen E, Bosshardt DD, von Arx T. Haemostatic effect and tissue reactions of methods and agents used for haemorrhage control in apical surgery. Int Endod J. 2010;43:57-63.

23. Pescatore C. A predictable gingival retraction system. Compend Contin Educ Dent. 2002;23:7-12; quiz 18.

24. 24. Shannon A. Expanded clinical uses of a novel tissue-retraction material. Compend Contin Educ Dent. 2002;23:3-6; quiz 18.

25. Wang N, Knight K, Dao T, Friedman S. Treatment outcome in endodontics-The Toronto Study. Phases I and II: apical surgery. J Endod. 2004;30:751-61.

26. von Arx T, Jensen S, Hänni S. Clinical and radiographic assessment of various predictors for healing outcome 1 year after periapical surgery. J Endod. 2007;33:123-8. 